\title{
Discussion on challenges and its countermeasures of MOOCs to undergraduate teaching majoring in Internet of things in China
}

\author{
Peng Guo ${ }^{a}$, Naixiang $\mathrm{Li}^{\mathrm{b}}$, Tonghai $\mathrm{Liu}^{\mathrm{c}}$ \\ College of Computer and Information Engineering, Tianjin Agricultural University, Tianjin, China \\ 300384 \\ a super_guopeng@163.com, ${ }^{\mathrm{b}}$ linaixiang@tjau.edu.cn, ${ }^{\mathrm{c}}$ liutonghai@tjau.edu.cn
}

Keywords: MOOCs; Internet of Things; Challenges; Countermeasures

\begin{abstract}
As a kind of new-generated teaching mode, MOOCs brings education great challenges as well as excellent opportunities. We discuss current situation of Internet of Things teaching in China, analyze challenges that MOOCs brought to Internet of Things education, especially on professional course teachers, teaching environment and teaching effect, we also discuss corresponding countermeasures. Utilizing promotion of MOOCs teaching idea to education development, improving the teaching skills of professional teachers and practice teaching condition will push forward development of undergraduate education majoring in Internet of Things in China.
\end{abstract}

\section{Introduction}

MOOCs, which means massive open on- line course, emerged in 2008[1], MOOCs developed very quickly in USA in 2011, and had tremendous, profound impact on college education. According to The New York Times, 2012 became "the year of the MOOC" as several well financed providers[2]. In 2013, 12 universities which included top universities in China such as Tsinghua University, Peking University and Shanghai Jiaotong University cooperated in construction of MOOCs in Chinese, many other universities and colleges joined this MOOCs platform, or developed their own MOOCs system. In less than a year, more than 300 millions university students studied via Chinese MOOCs system[3-4].

MOOCs is a completely new educational mode. In MOOCs, activities such as lectures, experiences, class tests, and other teachings are implemented with the Internet. Besides teaching videos and exercises as in traditional teaching, MOOCs platform also provides interactive forums to students, builds platform among teachers and students. Compared to traditional teaching in classroom, MOOCs is more scientific and efficient in study and knowledge diffusion. Benefits to students who study with MOOCs include: (1) Students and teachers are not confined to geographical location, teachers can make their teaching contents into videos, and students study from teaching videos with Internet browsers and multimedia accessories. Where there are online computers or mobile devices, students can obtain quality educational resources. (2) MOOCs are not restricted by the time. Comparing to traditional study in classroom, students can carry out studies via MOOCs in spare time, and they can obtain desirable results both in jobs and study. (3) MOOCs are not limited with excellent teaching resources, excellent teachers improve their skills after many years' accumulation, but they are not vigorous enough to provide excess teaching, making their teaching into MOOCs, as many students as possible will share these teachers' high quality teaching resources.

\section{Current situation of undergraduate teaching majoring in Internet of Things}

Internet of Things is the network of physical objects embedded with electronics, software, sensors and other devices to achieve greater service by exchanging data among manufacturers, operators, providers with connected devices based on International Telecommunication Union's Global Standards initiative infrastructure[5]. Internet of Things connects any "things" via Internet with infrared sensors, Radio- frequency identification (RFID) Global Positioning System, Laser scanner 
and other sensing devices in accordance with protocols, and exchange information to communicate to realize intelligent recognition, positioning, tracing, monitoring and management. With the characteristics of strong discipline, combination of industry and universities' research, and features of system engineering, Internet of Things engineering involves many different fields and belongs to inter-discipline. Exercise practice and innovation ability are paid more attention. At present, technologies of Internet of Things in China are still in the developing stage. There are problems such as low level of maturity of key technical products and integrated system, lacking of professional personnel and so on, there is an urgent need to accelerate training of Internet of Things professional and technical personnel [6]. Current situation of Internet of Things engineering is summarized as follows:

- Curriculum system and teaching mode of Internet of Things are urgent to develop or to improve.

- Internet of Things specialty is a multi-disciplinary subject, which requires courses teachers mastering more specialty knowledge than other teachers.

- Application areas vary widely, this requires using professional fields of practice teaching environment to carry out instruction.

- Students majoring in Internet of Things wish to improve their practical ability, and apply what they have learned to jobs after their study, their requirements on content and learning effect are very high.

\section{Challenges and its countermeasures of MOOCs to teaching majoring in Internet of Things}

\section{(1) Professional teachers being needed to adapt to the entirely new MOOCs' teaching}

In China, the first undergraduate students majoring in Internet of Things enrollment happened in September, 2010[7], and these students graduated in June, 2014. Compared to other specialties, history of Internet of Things is short and courses teachers have few teaching experience of Internet of Things as references. On preparation of teaching materials, teachers have to select textbooks among many alternatives, because candidates belong to multi-discipline crossing subject, it is a hard work to teachers who are not familiar with Internet of Things engineering. Teachers should bring different contents together and understand thoroughly what should be taught, and form their own teaching contents for different application fields. Compared with other engineering specialties, teaching duty of Internet of Things is more stressful in time, and teaching task is more difficult.

MOOCs is a new mode for professional teaching. Teaching work of Internet of Things engineering is started from scratch, thus, on selection of course system and teaching mode, the teachers will not be influenced by traditional habits and existing facilities, and they should not worry about cohesion between existed facilities and MOOCs, they should boldly explore and innovate, adopt advantages of MOOCs, and construct completely new teaching mode and environment of Internet of Things. Teachers from different industrial fields combine their own disciplines in Internet of Things teaching and integrate their courses into MOOCs. They can also overcome problems found in MOOCs teaching, this is conducive to teachers to consult to experts and scholars, and to reduce the time needed for preparing the lesson and improve teaching efficiency.

(2) Higher Requirements on teachers' background knowledge and scientific literacy

The traditional teaching mainly uses the one-way mode. Teacher seriously presents teaching in accordance with the syllabus, and students passively listen to the teacher, most of the time in class is used by the teacher to give lecture, and students seldom participate in the teacher's lecture, interaction between the teacher and students is only carried out in discussion section of a class. In MOOCs, students study through teaching video-on- demand with browser software, each teaching video only last 10-20 minutes, they can ask their teacher a question after watching a video, the question may be their doubts in the video, or other problems associated with teaching videos. This requires teachers to have broad visions and profound knowledge in their profession and response quickly to students' problems. 
Setting up professional teaching team of Internet of Things with freshmen and experienced teachers. We can select experienced teachers from teams such as computer science, network, communication, mechatronics or control engineering, these teachers have plenty of experiences and sound knowledge in their field. We can also attract young teachers with a doctorate in fields mentioned above to join Internet of Things teaching team. These young teachers have a deeper professional knowledge and higher scientific literacy after scientific research as PHD candidates. Combination of rich experiences, solid knowledge of old teachers, high work passion and scientific literacy and a wealth of relevant areas of scientific research experience of freshmen and advanced teaching mode of MOOCs will promote professional development of Internet of Things teaching.

\section{(3) Higher requirement of Internet of Things teacher's practical abilities}

Students make comparisons of teachers' teaching in daily study when choosing elective courses through MOOCs, teaching contents and teaching methods of teacher's have great influences on the choice of students. The teaching objective of Internet of Things engineering requires that students can master Internet of Things technology after study. But teachers' practical ability has great influence on the students' learning effect. Those teachers who pay attention to theory teaching, and neglect practical teaching will face the situation of few students studying in their elective course.

Professional course teachers can improve their practical teaching ability through many ways. Internet of Things technology and application attracted attentions from the authorities, the industry and education communities in China, construction specialty and teacher training are supported by the authorities. Course teachers can improve their abilities via the following means:

(1)Applying Internet of Things science foundation projects or join in research teams related to Internet of Things projects. They can enhance knowledge accumulation, expand horizons and improve their scientific literacy in scientific research.

(2) Young teachers with master degree studying for doctorate. During their study, candidates participate in their superior's scientific project research, strengthen scientific research ability, scientific papers writing ability. After learning from doctoral tutors, they accumulate project development abilities, research experiences.

(3) Young teachers can take exercise in INTERNET OF THINGS enterprises by taking part in production and R\&D to improve their ability of practice. They can understand professional background and actual needs of the talents in different field of the Internet of Things, master production, research and development technology of the enterprise to improve their practical development abilities.

(4) Requiring teachers to rearrange teaching contents, interests and textbook organizations

In traditional teaching, teachers make lectures on contents they prepared according to syllabus and students passively listen to them, teachers pay more attention to knowledge delivery. Activities among teachers and students are carried out face to face, teacher's voices, changes in mood and intonation and interventions to those absent- minded students have great influences on study effect. The leading role of the teacher in classroom largely determines learning effects of students. While in MOOCs, teachers and students contact via Internet, some students may be far away from their teachers, they may be separated by thousands of miles, students may not meet their teachers even completing their course study. Students have no direct impression of their teachers, effect of teachers on students in the traditional classroom is few in MOOCs, and it is hard for traditional teaching to obtain desired result in MOOCs.

Course teachers should improve interests of lectures and teaching contents. To obtain a good teaching effect, Internet of Things teachers should pay more attention to teaching contents, interests of teaching and text organization of lectures. If the expression of a teacher is single and contents are lack of change, no matter how important the course is, it is very difficult to excite students to study and results will not be good. In MOOCs, teachers can not interfere with absent-minded students. To deal this occurrence, teachers are required to anticipate where students may be weary of studying because of boring content during preparation of teaching video, and process carefully teaching content, teaching interest and text organization. Teachers can insert related demo using multimedia in 
theory teaching to avoid completely boring theoretical teaching, they can also add anecdotes from some experts and scholars or social applications related to teaching content to stimulate students' interest to improve students' learning effect.

\section{(5) Higher requirements on Internet of Things teaching content}

Students will make comparisons among professional teachers and their courses when they select courses via MOOCs. They require teachers to afford lectures in sophisticated manners and express flexibly, they may also require their studies are practical because many students regard employments in the future as the primary factor in course selection. On practical teaching, students want to study for the purpose of application and the content of practical teaching is closely related to the needs of the society.

Cooperation between enterprises and universities should be strengthened. The universities should establish practical bases with enterprises, hire technical experts from production or research branches of enterprises to carry out practical teaching. As an emerging profession and domestic demand for increasingly urgent personnel training, Internet of Things teachers accepting teaching training may be recognized and supported by the authorities when compared to others traditional disciplines, this is beneficial for Internet of Things teachers to master what they will teach in the future.

\section{(6) Higher requirements on teaching effect}

Whether students choosing a course with enthusiasm or not depends on the employment in the future, In traditional teaching, theory teaching from textbooks is the main content, examination is chosen as the main evaluation mode, and practice teaching is used as an assistant, the effect of this teaching mode cannot generate results Internet of Things students required.

Increase the proportion of case teaching in teaching contents and introduce project oriented assessment method. Internet of Things teachers should discard teaching methods paying more attention to theoretical knowledge, select practice cases from Internet of Things application in our society and use project assessment method to examine study effect.

(1)Teachers explain specific project cases firstly, and require students to develop a practical project of Internet of Things, students gradually expand their project works, integrate basic knowledge of Internet of Things that have be learned into design and development of the project. In implementation, teachers put forward project requirements via MOOCs, students join in a team voluntarily and make panel discussion in their teams to determine the initial research objectives and tasks and feedback to their teacher. Research team members determine the ultimate goal and task under the teacher's guidance.

(2) Secondly, students develop a project development plan, a work procedure and a system design solution, and send them to their teacher via MOOCs, the teacher audit materials that students submitted, and propose amendments. After several information exchanges between the teacher and the research team, results will be proved by the teacher.

(3)Thirdly, students select their team leader, make project division according to each member's capacity in their team, construct development environment, design hardware and write computer program in accordance with project development plan.

(4)Finally, completing program testing and documentation before oral examination for final research project report.

Through steps mentioned above, students can improve practical abilities to develop project, paper writing abilities and collaboration capabilities in works, these are included in the purpose of improving Internet of Things teaching effects.

\section{Summary}

Using multimedia technology and Internet technology to explore innovation on teaching mode is a great change of traditional education, this has drawn worldwide attention. Exploring theory and method of MOOCs, applying MOOCs to research of new curriculum and seeking methodologies on improving students studying enthusiasm and teaching efficiency will play a great role in promoting 
education's development. Applying new concepts and methods from MOOCs to Internet of Things engineering teaching can accelerate Internet of Things development of curriculum system, practice teaching and teaching methods, all of these factors are influenced by Internet of Things professional courses teachers, the improvement of Internet of Things professional teachers' abilities will greatly promote teaching.

\section{Acknowledgement}

This paper is supported by Tianjin university undergraduate teaching quality and teaching reform research project (E01-0809), Research and reform project of Tianjin Agricultural University undergraduate education (2014-B-06) and Tianjin Municipal Science and technology correspondent special project (14JCTPJC00540).

\section{References}

[1] Wikipedia. Massive open online course. https://en.wikipedia.org/wiki/Massive_open_online_course

[2] Pappano Laura. "The Year of the MOOC". The New York Times. Retrieved 18 Apr. 2014.

[3] Dong Lingling. Impact and its countermeasures of MOOCs to traditional higher education. China adult education. 2013, (23): 145 146 (in Chinese).

[4] Wu Zhendong, Peng Xiaohua. Chinese MOOCs is bringing a Catfish-style influence to college education. Xinhua Daily Tele- graph. 2013-10-28 . page 7. (in Chinese).

[5] Wikipedia. Internet of Things. https://en.wikipedia.org/wiki/Internet_of_Things

[6] Wu Gongyi. Thinking on the construction of the teaching system of the Internet of things. Computer Education.2010, (21):26 29. (in Chinese).

[7] Sogou Encyclopedia. Internet of things technology. http://baike.sogou.com/v67765625.htm.(in Chinese). 